\title{
Infrastructure Sharing Among Ghana's Mobile Telecommunication Networks: Benefits and Challenges
}

\author{
Sylvester Hatsu ${ }^{1}$, Ujakpa Martin Mabeifam², Philip Carlis Paitoo ${ }^{3}$ \\ ${ }^{1}$ Computer Science Department, Accra Polytechnic, Accra, Ghana \\ ${ }^{2}$ Faculty of Information Technology and Systems Development, International University of Management (IUM), Dorado Park Campus, \\ Windhoek, Namibia \\ ${ }^{3}$ Graduate School, Ghana Technology University College, Takoradi Campus, Accra, Ghana
}

Email address:

shatsu@apoly.edu.gh (S. Hatsu), ujakpamabeifam@gmail.com (U. M. Mabeifam), ellycarly14@gmail.com (P. C. Paitoo)

To cite this article:

Sylvester Hatsu, Ujakpa Martin Mabeifam, Philip Carlis Paitoo. Infrastructure Sharing Among Ghana's Mobile Telecommunication Networks: Benefits and Challenges. American Journal of Networks and Communications. Vol. 5, No. 2, 2016, pp. 35-45. doi: 10.11648/j.ajnc.20160502.14

Received: March 25, 2016; Accepted: April 20, 2016; Published: May 12, 2016

\begin{abstract}
In Ghana network companies such as Vodafone, Mobile Telecommunication Network, Airtel, Tigo, Expresso and Globacom (GLO) are experiencing increasing subscribers for voice calls, internet and video services. Competition in the industry has been intensified making service providers searching for innovative strategies to survive the competition. Strategies adopted to survive the stiff competition include rebranding, infrastructure sharing and mergers and acquisitions. This study focuses on infrastructure sharing as a strategy to reducing cost for these telecommunication service providers in Ghana. Mobile telecommunication industry in developing countries has players a remarkable role in providing services to large portion of the population. Despite the achievement in reaching large numbers, extra efforts are needed to increase the mobile service penetration. In increasing the penetration, attention needs to be focused on the rural areas. High network infrastructure cost has been the major problem. As operators strive to recoup investment cost associated with building the expensive infrastructure, customers tends to suffer from high network charges/ prices. Infrastructure sharing presents itself as a means of lowering network deployment cost, especially in rural and marginalized areas. Sharing has an advantage to stimulate migration to new technologies and mobile broadband deployment. Arguably, another advantage is the stirring up of competition between mobile operators and service providers, when safeguards are used to prevent anti-competitive behavior.
\end{abstract}

Keywords: Telecommunication, Competition, Mobile, Telegraph

\section{Introduction}

\subsection{Background of the Study}

The current liberalization, privatization and globalization concept which Ghana embraced during the economic recession period of the 1980s has resulted in the complete removal of Government's hands in active business and economic activities in the country. It is assumed that through liberalization, economic and allocative efficiency will be achieved in the country which will result in total national development. This approach is also to correct the balance of payment deficit and result in higher Gross Domestic Product (GDP), which is a necessary indicator for economic development of any country. Goods and services will be allocated by "invisible hands" in the words of Adam Smith. One clear result of liberalization, privatization and globalization, embarked by the government of Ghana in the 1980 s, was the upsurge of telecommunication industry operators in Ghana, after the deregulation of the telecommunication industry.

In Ghana Government's corporation, known as the Ghana Post, Telephone and Telegraph dominated and monopolized the telecommunication industry of Ghana. Liberalization, privatization and globalization policies of the Bretton Woods organizations in Ghana led to the relaxation of deliberate controls and policies which seeks to protect and monopolized 
state organizations to favour the encouragement and/or engagement of private ownership in business. The period from1994 to 2000 saw a dramatic competition within the telecommunication industry of Ghana. This period, characterized by liberalization and privatization, experienced a shift from government's controlled Ghana Post, Telephone and Telegraph to a privatization, technically termed deregulation of the telecommunication sector. This resulted in a competitive telecommunication industry, which allowed the operation of private internet and/or mobile telecom network providers in Ghana, after 1994.

To [1] Ghana's adoption of liberalization, privatization and globalization policy of the World Bank within its telecommunications sector, led to the birth of a development and implementation of a policy document known as the Accelerated Development Program (ADP). This programme was initiated in the year 1994 and spanned to the year 2000, meaning a six years deregulation programme of the telecommunication Industry. The Accelerated Development Programme was a six years comprehensive development plan which was meant to restructure the telecommunication industry of Ghana. Drawn together with the assistance from the World Bank consultants, the policy objectives of the Accelerated Development Programe, according to [1] were to achieve a density between 1.5 and 2.5 lines per 100 people, to provide payphone facilities in the whole country (both rural and urban) to improve public access to communication and improve the coverage of mobile services in the country. The other objectives were to encourage the ownership and operation of Ghanaian telecommunication companies and finally the creation of a national body called the National Communication Authority (NCA), to regulate and control the activities of the telecommunication networks. Telecommunication industry has made a remarkable improvement in Africa and has become one of the robust industries. The service has expanded to include innovative packages such as accessibility to internet, banking and retail transactions [2] Through mobile telecommunication, Africa has reached 400 million mobile subscribers, many of which resides in remote areas with no fixed telephone connectivity. [3] on a telecommunication industry growth survey, reports a growth of 9.3 percent (from the year 2002 to 2007), making the industry one of the fastest growing in the world.

In Ghana, mobile telecommunication market has experienced a geometric growth making it one of the fastest on the African continent. Sustaining such a market carries for itself a huge cost burden. Mobile telecommunication investors and operators have no option than to spend huge capital expenditures on assets/infrastructure to become competitive on the market. Thus, telecommunication industry invests heavily in infrastructure, equipment, logistics and software to improve service delivery services for its clients. Factors such as customer sophistication, increased advancements in technology and globalization makes it imperative for mobile telecommunication service providers to invest in such items, which comes with huge cost. Normally, these investments take a longer time for these mobile telecommunication service providers to recoup their investment. However, they have no option than to acquire the equipment to survive the competition. Management of such companies spends time to think about strategies to reduce cost and increase revenue and profit margins. Some of the areas of focus to achieve cost reduction and increase revenue and profit margins are:

1. To continue with the acquisition of state of the art technology (thus increase assets- transmission, equipment).

2. Introduction of new products and services and strengthening of marketing of service and products.

3. Efficient management of debt and the practice of stiff internal controls.

Acquisition of infrastructure has become an inevitable part of the operations of these mobile telecommunication companies. These infrastructures are expensive to acquire. Mobile telecommunications regulators, together with policy makers in the industry are encouraging the sharing of infrastructure globally.

A benefit to the mobile telecommunication is seen from enhanced services.

Sharing induces and intensifies competition among the mobile telecommunication operators, thus also reducing tariffs on the consumer. Resource conscious advocates argue in support of infrastructure sharing as an environmental friendly approach as it saves the depletion rate of the environment. Also, savings can be made on energy consumption of infrastructure. Aesthetics wise, infrastructure sharing is a plus on street furniture. Mobile telecommunication companies in Ghana have started practicing infrastructure sharing. The idea is to reduce cost and provide quality services which meet the pocket of every Ghanaian. This sharing has introduced special advantages and challenges of which this study is interested to unearth.

\subsection{Problem Statement}

Growth and survival of any company, of which mobile telecommunications companies are included, is intrinsically linked to globalization, productivity, quality, and satisfaction of customers. The needs to attract and retain customers are necessary conditions for growth and survival of these mobile telecommunication companies. Thus, making the customer the centre of attraction on which business revolves and therefore the major focus for business success. So sharing is like a compulsory acquisition of infrastructure from Econet who has invested a lot in infrastructure building for the benefit of other companies who have not spent on building infrastructure.

\subsection{Objectives of the Study}

The general objective of the study is to investigate infrastructure sharing among mobile telecommunication networks in Ghana. Specifically, the study will achieve the following objectives. These are to: Assess the types of infrastructure mobile telecommunication networks share 
among themselves; examine the benefits of mobile telecommunication infrastructure sharing;

\subsection{Research Questions}

The following research questions guided the study. These are:

What types of infrastructure are mainly shared among the telecommunication networks?

What are the benefits of infrastructure sharing?

\subsection{Significance of the Study}

A study of this nature makes the government and the mobile telecommunication network operators, academia and the general public. The government is one of the primary drivers of infrastructure sharing, through its regulatory body called the National Communication Authority (NCA). The government seeks to ensure that mobile telecommunication operators share infrastructure to reduce their operational cost. The savings made can be channeled into other areas such as improving quality of service for customers. Reduction in operational cost can also manifest in less service charges, thus saving customers from exorbitant charges from network operators. It will aid the National Communication Authority in making appropriate policies in the areas of infrastructure sharing.

\section{Literature}

\subsection{Generic Strategies: Theory}

- It is important for a firm to choose a position [4]. These positions, in the words of Porter, called variables are central to position; Porter names the two variables as: competitive advantage and competitive scope.

- Porter argues that a firm's success in the long run, relative its competitors, is its sustainable advantage. Two types of competitive advantage were identified: lower cost and differentiation. Porter explains lower costs as the ability to design, produce and market a comparable product at more cost-efficiently than its competitors. In the long run, lower costs translate into higher returns. Higher returns are attained when prices are less or near the competitors' prices. The mobile telecommunication industry in Ghana is highly competitive and technology intensive. Customers are always looking for cheaper means of enjoying services and tend to accept companies which provide better services at lower cost. However, for a mobile telecommunication industry to provide less costly and improved services, it must invest more into infrastructure. Acquiring infrastructure is expensive. Those who are able to afford these expensive usually charges higher service cost in a view of recouping the cost of infrastructure. However, infrastructure sharing presents one of the possible means for mobile telecommunication companies to achieve Porter's competitive advantage and serve in the industry.
- The ability of the firm to provide unique and superior value to customers, in the areas of product quality, special features, after-sale service is referred to as differentiation. Achieving competitive advantage, as explained by Porter, helps to achieve higher productivity compared to the firm's competitors. Competitive advantage makes a firm productive using fewer inputs, with higher revenues per unit. Porter cautions on the impossibility to achieve quality service at lower cost, since inherent in good performance, quality service is more cost. A successful strategy, such as infrastructure sharing, pays close attention to both.

- Competitive scope variable looks into the breadth of the firm's target within its industry. Questions on what to produce (products), distribution channels to use, targeted buyers, geographic areas to sell products and the related competitive industries it will operate. The segmented nature of industries makes competitive advantage an important concept. Another fact that asserts the importance of competitive scope is that firms can sometimes gain competitive advantage from breadth through competing globally or from exploiting interrelationships by competing in related industries. Though different strategies exist, competitive advantage is inherently central to any strategy a firm adopts. Achieving competitive advantage requires choice making. Making a choice of competitive advantage and scope spells out where the firm can strategically achieve the advantage. Infrastructure sharing among mobile telecommunication network provides the best strategy for the achievement of such an advantage to the companies on board.

\subsection{Defining Infrastructure Sharing}

- Resource sharing here is equated to mean same as infrastructure sharing. Infrastructure sharing, according to [5] is the same use of part or parts of infrastructure by more than one mobile telecommunication operators. Resource sharing is country specific and thus its implementation varies from country to country. Due to variations, different legal backing documents exits on support of infrastructure sharing. Coordination, is one of the forms through which sharing can be made possible. Coordination involves exchange of information on infrastructure use. This result in more efficient online or offline use of resource(s) [5].

- Infrastructure sharing gained attention during $3 \mathrm{G}$ development in Europe through [6] spectrum licensing and agreements on sharing network.

\subsection{Ghana's Mobile Telecommunication Industry}

The telecommunication industry in Ghana has a long history. In 2003, there were less than one million telephone lines in Ghana, the number has increased to more than 17 million at the end of 2010 (75 percent mobile penetration). Mobile voice subscriptions from the month of January to 
August 2015 have been presented here. Increases have been recorded in January $2015(30,629,604)$ to August 2015 $(32,826,405)$, according to the National Communication Authority in 2015.Mobile communications sector's growth has been attributable to the deregulation policy.

\subsection{Drivers of Infrastructure Sharing}

Globally, trends towards voluntary, unlike mandatory, sharing is been pictured and championed. Intensive growth together with competition from other operators and rising trend in the cost of capital expenditure, associated with expending network to reach more operators [7]. Infrastructure sharing has been the way out. Infrastructure sharing reduces risk [8] through sharing of site building risk among operators. Sharing has been championed on commercial lines as it serves the following purposes. These are:

a It allows Mobile Network Operators to avoid permit securing challenges in building new sites.

b Merges existing networks. Sharing of risk in areas with low population densities among the mobile network operators.

c Encourages reduction in cost, whiles increasing the efficiency through pooling of spectrum.

d Cuts down on duplication. Saved resources are channeled to other areas such as product innovation (likeLTE, mobile broadband).

e Drivers of infrastructure sharing are mainly classified into two [7]. These are government's regulatory and competition perspective.

\subsection{Government's Regulations}

- Regulations of the National Communication Authority affect decisions of infrastructure sharing. National Communication Authority of Ghana usually comes in with such policies to save the country and its citizens. For example, the country is currently facing power challenges. Sharing infrastructure is one of the strategies to reduce power consumption of multiple infrastructure belong to different mobile telecommunication operators. Also, there have been public out-cry on the damaging and health hazards that mobile telecommunication infrastructure, such as mast, poses to the health of the immediate environments it is constructed. There was a mass protest in Accra in 2009 after the collapse of a mast killing one person and injuring others. [9] Estimates that 40 per cent of the public complains of telecommunication mast were health related concerns. 33 percent proximity to residential property and schools and 27 per cent were lack of informed consent, meaning the communities were not sufficiently consulted before erecting the mast. Fumes and noise from generators were also reported by community.

- Infrastructure sharing becomes one of the options for reducing, as much as possible, the number of such masts. Also, through infrastructure sharing the operational cost of mobile telecommunications operators are reduced by an average margin of 60 percent. This shaving can be channeled into other areas of production, which are equally important for the provision of better services to mobile subscribers. The cost of constructing a mast is estimated to be US\$ 250,000. After constructing such an infrastructure, mobile telecommunication operators have no option than to shift the cost of constructing such an infrastructure to the customer, who is the weakest in this relationship. Customers are charged higher for mobile services. So infrastructure sharing tends to reverse such a trend. These are the major reasons for the government to champion infrastructure sharing in Ghana.

- In Ghana, health, aesthetics and safety were main argument for the involvement of government to encourage infrastructure sharing in the year 2009. An Inter-Ministerial Committee was commissioned to develop a framework to enhance infrastructure sharing. The commission involved the Ghana Civil Aviation Authority (GCAA), National Communications Authority (head), Ghana Atomic Energy Commission (GAEC), Environmental Protection Agency (EPA), Metropolitan, Municipal and District Assemblies. The task of the commission was to develop a guiding document for the deployment of communication towers. The head was to collaborate with industry and other stakeholders.

- Additionally, Sharing prevents duplication of infrastructure. It enables investments in financially underserved areas. [10] Argue that sharing results in improved customer service and product innovation. They further positions four important regulatory dimensions for government's interventions. These are: pricing, policy, safeguards and policy enforcement (Table 1). National Communication Authority encourages the sharing of infrastructure that carry with no risk of lessening of competition. The infrastructure includes: Antenna, Masts, tower structures and Rights of Way. Others include Space in buildings, Trenches, Electric power and Ducts.

Table 1. Regulators' Intervention areas in Infrastructure Sharing.

\begin{tabular}{ll}
\hline Category & Description \\
\hline Regulatory & $\begin{array}{l}\text { Regulatory authorities should create in collaboration with } \\
\text { local authorities and municipalities, policy that encourages } \\
\text { sharing. The policy should be such that encourages } \\
\text { incumbents and new entrants to balance their shared } \\
\text { network rollout. Telecom laws facilitate, mandate or } \\
\text { empower the regulator to enforce infrastructure sharing. }\end{array}$ \\
& $\begin{array}{l}\text { Cost-based prices should be applied so as to allow operators } \\
\text { to recoup their investments. Each network element should } \\
\text { be priced separately so as to allow the requesting operators } \\
\text { to pay only the elements that they need. In case of new } \\
\text { Pegulation } \\
\text { networks and increase of existing capacity, costs should be } \\
\text { shared. Late entrants should compensate existing partners } \\
\text { for any shared investment before being given access to the } \\
\text { network. }\end{array}$ \\
\hline
\end{tabular}




\begin{tabular}{ll}
\hline Category & Description \\
\hline & $\begin{array}{l}\text { Regulators should ensure that infrastructure sharing is in line } \\
\text { with the general regulatory standards of telecom sector: } \\
\text { transparency, efficiency, independence and non- } \\
\text { discrimination. Capacity should be sold on first come first } \\
\text { served basis and the regulator should intervene to distribute } \\
\text { scarce resources when it is necessary. Unused capacity } \\
\text { Regulatory } \\
\text { Safeguards } \\
\text { should be returned and operators should not order excess } \\
\text { capacity. The operators could get penalties if their ordered } \\
\text { capacity exceeds the utilized capacity by a certain } \\
\text { percentage. Regulators should constantly monitor the } \\
\text { sharing activities. Physical separation of shared network } \\
\text { components can be used as long as it does not affect } \\
\text { efficient sharing. }\end{array}$ \\
$\begin{array}{l}\text { Sharing should be encouraged by creating incentives. } \\
\text { Penalties should be given to the operators that fail to comply } \\
\text { with the adopted regulation. Regulators should intervene to } \\
\text { solve disputes and clearly define the dispute-resolution } \\
\text { procedures. Compliance should be monitored by regulators. }\end{array}$ \\
Policy
\end{tabular}

Source: Adopted from [11]

\subsection{Quality of Service}

Besides lower charges for service, quality of service provided by the network operators have be of prime focus. Quality of service is the main factor distinguishing among the competing mobile telecommunication companies. With the power in the hands of the subscriber to shift to other mobile telecommunication service with better service, it behooves on the mobile network operators to improve service provision by the acquisition of infrastructure; which has become possible under the jacket of infrastructure sharing.

\subsection{Enhancement of Profitability}

Infrastructure sharing is one of the strategies for reducing operational cost of mobile telecommunication companies. Capital expenditure is also reduced with opportunity for higher Return on Investment. It has positively impact on Profit and Loss account.

\subsection{Demands from New Technologies}

The introduction of new technologies such as $3 \mathrm{G}$ and its resultant use of Wi-MAX (Worldwide Interoperability for Microwave Access) have made it necessary to share network to improve services. WI-Max will increase the demand for sharing.

\subsection{Benefits of Infrastructure Sharing}

Improving quality of service of network operators and expenditure reduction has been seen as the immediate benefit of infrastructure sharing [12]. Earning of extra income from rentals of non-core assets, new entrants enjoys faster market entry and the focus it gives operators to focus on other important services such as customer service were the further benefits (ibid). Through sharing, customers, who are at the receiving end, enjoy better charges for mobile phone services and areas considered not to be economically feasible to receive mobile networks, get the chance to network. It also serves to add up esthetics to the city. From the perspective of network operators, benefits of infrastructure sharing manifests in cost savings [10] 30\% savings on capital and operational expenditure from passive sharing. Further, Ghandhi, an Indian telecommunication expert, opines passive infrastructure sharing allows operators to focus on marketing and sales areas. Leasing of towers generates additional income. Entry of new operators into the market becomes easy. To the environmentalist, negative environment and health hazards perceived to be carried in the form of emissions are reduced through infrastructure sharing.

\subsection{Models of Infrastructure Sharing}

Five different sharing models have been explained. Choice and/or combination of sharing models depend on some factors. The primary among them is the operator. Through theoretically, it is possible to share almost everything, regulatory authorities, sometimes, prohibits the sharing of certain configuration. Possibly, theory makes it easy to, say level one and level three, without sharing level two. Operators can share sites and masts. Additionally, they share the radio network. Another sharing is to geographically divide the country. They can then build in different areas. Typical mobile network infrastructure has been presented in. Each operator has then its individual network but offers extended coverage, known as national roaming, to other operators and their customers. Operators, finally, deploy a common shared network. On this they all elements are shared on levels: from one to five, Detail explanation of the model is provided in Figure 1.

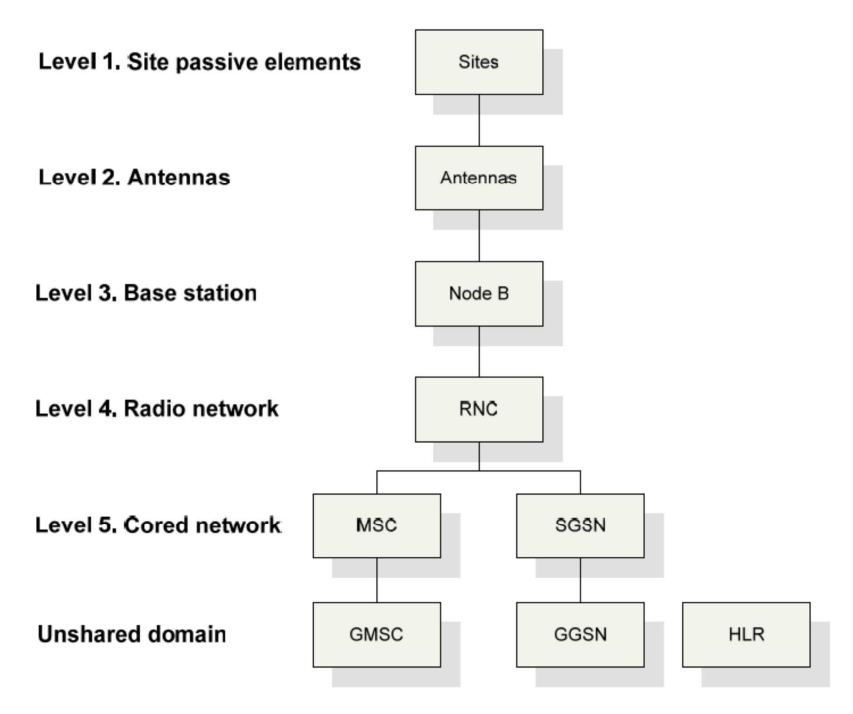

Source: Adopted from [13]

Figure 1. Different Technical level Infrastructure Sharing Models

\subsection{Sharing Site and Mast}

This is the simplest form of network sharing. Under this operators have common facilities and site. Passive elements are shared on level one. All passive and active elements on site are involved. Examples of passive and active elements are: antennas, sites, cooling, masts, civil works, power and 
towers [14]. Areas with challenges such as delayed or impossibility in getting building permits. Also municipality with limited space and restrict the installation of separate antenna, are good for this type. With this, challenges arises from the charge one operator can impose on the other operator. Employees of one operator can damage the equipment of the other. Lastly, when to plan for new site is also a challenge. The advantages here are the simplicity and the cost savings are huge [15]. There is a positive effect of sharing and overall expenses, as overall expenses reduces from sharing cost associated with sites. Civil works constitutes $30 \%$ and site rental $20 \%$ of network CAPEX and OPEX respectively. Reduction of visual pollution of mast is an additional advantage [14]. Infrastructure sharing does not minimize competition to any appreciable level.

\subsection{Geographical Sharing}

Operators can decide to build in different geographic locations of the country, and strategically, enhance nationwide coverage through national roaming advantage. This strategy promotes the fast growing and cost reduction method for the network operators. For instance, one operator can build in the northern part of the country, while another builds in the southern part. This is an efficient way of providing coverage while each operator keeps its individual network. The sharing is not on any certain technological level, but each operator holds the entire infrastructure (on all levels) in its own part of the network.

Regulatory authorities in some countries have restrictions that can affect this model of sharing. As stated earlier, each operator in Sweden must own radio infrastructure that covers at least 30 percent of the population. Consequently, it is not possible for one operator to only cover a small area and use national roaming to get access to another operator's network in other parts of the country. However, when the operators split the total coverage in two equally large parts, this restriction is fulfilled. Further, the network operators are often willing to roll out separate networks in urban areas, as the income in these areas justifies separate networks. In such areas, the own network is the preferred one. One problem with national roaming is that many operators have the same target groups, and thus identify the same target areas within a country for their network deployment.

This can reduce the possibility of agreeing on larger national roaming agreements [14]. The operators probably solve problems of this kind by constructing contracts in a way that prevents one part from taking extensive advantage of the situation. Another problem is that the operators cannot be certain that their counterpart does not favour his own clients. There is a reason for one operator to favour large corporate customers. This can e.g., be done by tweaking the antennas in a way that the corporate customers get excellent quality while people on the street below the corporate customer's building get lower quality [14]. There are also complex business issues. Operators must agree on roaming prices, quality and capacity guarantees, and how the interfaces toward the customers are dealt with. Furthermore, agreements on how to deal with customers of third party network operators must be reached. This last problem becomes even more complex if the user visits urban areas where there is overlap in coverage [14]. Geographically split networks have certain effects on competition. National roaming prevents operators from competing against each other on the network level. Factors such as coverage, capacity, quality of service (QoS), and reliability in the shared areas are the same for both operators [14].

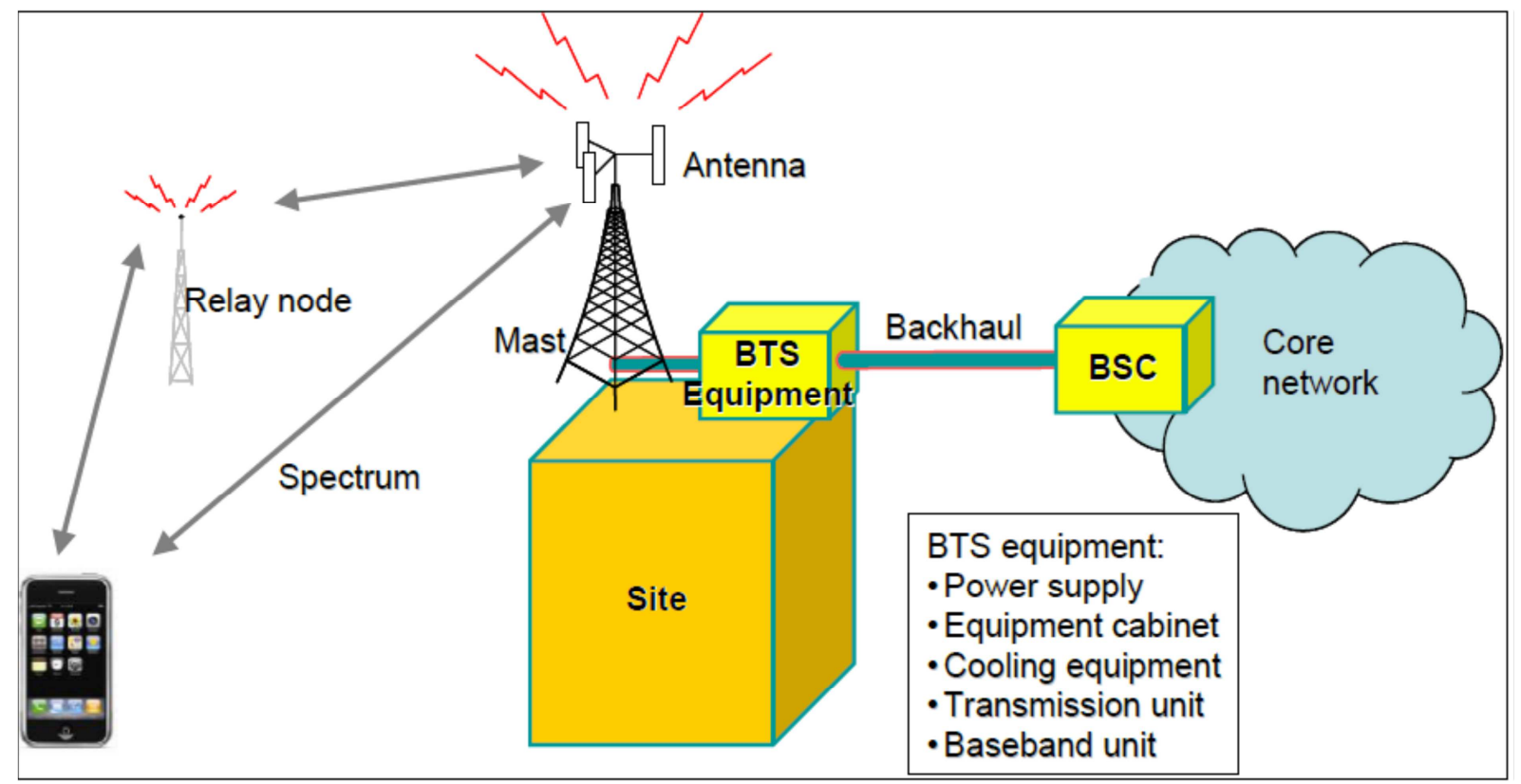

Source: Adopted from [5]

Figure 2. Infrastructure Elements of Mobile Telecommunication Industry. 


\section{Philosophical Underpinnings of the Study}

The study was qualitative in nature and draws its philosophical perspectives from the epistemological and ontological foundations of research. The general argument here is that social reality (in the case of infrastructure sharing) is socially constructed, through government's policies and discussions which involve the agreement of the companies. Infrastructure sharing did not emanate by it, however, the interactions of people and phenomenon, which is socially constructed brought, gave birth to it. Therefore it is influenced by society. Therefore any effort to study such a phenomenon must involve the active presence of the society.

This argument is in line with the assumptions of both subjective ontology and subjective/constructive epistemology. The subjective ontology and constructive epistemology both agree that the participants and the researchers influence the knowledge to be created ([16]; [17]. Their experience, perception and beliefs have impact on the kind of knowledge that is created [18]. Another assumption from the camp of the subjective ontology and constructive epistemology is that knowledge is constructed rather that it being discovered ([17]; [18]. The active involvement of the researcher and the researched in their natural setting will have influence of the kind of knowledge that is constructed. The subjective ontology and the subjective/constructive epistemology also influence the interpretive position of the research. The interpretive assumption believes that knowledge is constructed through the experience, perception and beliefs of the researcher and the participants in their natural setting ([18]; [16]; [17]. Data collected in such is full of words rather than numbers ([18; [19].As such, the best way to conduct such research is to adopt a qualitative approach and design to research.

\subsection{Study Design}

From the camp of [20] research design is an arrangement of conditions. These conditions capture data collection and analysis. Further, it is the conceptual structure which defines the environment of the research. Other authors call it a blueprint for the research. Blue print in it sense that is provides the framework and guidelines for data collection, measurement and finally to analysis. To the man on the street guideline outlining what the researcher will in his study, sweeping from hypothesis setting, operationalization and final analysis constitutes research design.

The research design adopted for this study is the qualitative and quantitative design. Qualitative design describes the characteristics of the study subject as put forth by the research objects (individual, group). It also involves diagnosis which determines the frequency of occurrence of an event or association with other things. Further diagnosis looks into the association between variables. Summary, descriptive studies makes predictions, narrate facts and characteristics of individual, group or phenomenon. This study is involved in narrating and description of infrastructure sharing practices among mobile telecommunication networks and to bring out their characteristics. On the hand quantitative design involves the use of statistical or mathematical formulas such as mean rankings, chi square, relative importance index, etc.

Requirements for the use of descriptive studies, according to [20] are: what the study seeks to measure and methods for measuring it. There should be a clear cut definition of study population. This study use the mobile telecommunication networks and focused on the management of these networks that are responsible for infrastructure; thus a clear cut population. The study has clearly defined specific study objectives with operationally defined variables within the objectives, making it easy to measure. The design made adequate provision against bias and the use of triangulation to ensure reliability of results.

\subsection{Population and Sample Size of the Study}

The population of the study includes all the mobile telecommunication networks operating in Ghana, together with their employees. All the six networks were used due to the small number for the study. Now for the employees, since all sharing issues are handled from the top management in the head office in Accra, only the population of the top management personnel from the six mobile telecommunication networks in Accra was used. Therefore all the mobile telecommunication networks operating in Ghana automatically became part of the population for the study. Staff like middle and low level staff were not considered due to their les role in the infrastructure sharing arrangement for the company.

The total number of all the top management staff for the six mobile operating companies was 30 . From the statistical table for determining sample sizes for study by [21], a population of 30 requires a sample size of 28 . However the study, adds an additional two of the sample size to make it 30. Similar [9] (which is on Ghana), [7] [13] (which is on Nigeria) and [11] (which is on Europe) (all discussed in literature review, under the sub-heading empirical review) made use of 30 as a sample size, making the sample size justified within empirical research circles within the topic.

\subsection{Sampling Procedure}

Non-probability sampling procedure was employed for the study. This was considered suitable for the study due to the qualitative nature of the study. Non-probability sampling procedure is that type of sampling which does not follow the law of probability; which gives each member in the population equal, non-zero and non-calculable chance of being included in the sample [22].

Purposive sampling method of non-probability sampling was employed to select respondents for the study. This method dwells on the expertise and judgments of the 
researcher to select respondents who best suit the objectives and purpose of the study. Respondents who deal directly with infrastructure management of mobile telecommunication networks, with in-depth knowledge on infrastructure sharing were considered and involved in the study. Five each was collected from each of the six mobile telecommunication operators in Ghana, focusing on the Head Office in Accra. This made a total sample of 30 respondents, selected from the top management personnel.

\subsection{Reliability and Validity}

Reliability and validity are very important aspect of research. They can be statistically calculated using quantitative approach and design. In the case of qualitative research, reliability and validity are done using different approach. Validity is defined as the ability and probability that a measurement is measuring what it is intended to measure [20]. Validity in a research can be content validity which is the extent to which an instrument or a research has adequate coverage of the subject under study, criterion related validity which comprise of predictive and concurrent validity and construct validity [20].

Validity in qualitative research can best be achieved using triangulation [18].Triangulation in qualitative research refers to the use of different data collection instruments to collect data ([18]; [20]. In such case, two or more different data collection is used in the collection of data in qualitative research. The use of observation and interview or questionnaire and interview in qualitative research promotes validity of the data that is collected. This by way helps to enhance the validity of the data that is collected and analyzed. The stability and equivalency of the data that is collected and analyzed ensure reliability of research. The conformity of data collected by a researcher to that collected by a different researcher on the same study and participants is stability. Stable data over a period of time promote the reliability of research [20].

\subsection{Data Collection Instrument}

Primary data was collected using one set of semistructured interview guides for all the respondents selected from the various mobile telecommunication networks operating in Ghana. Semi- structured interview schedules were designed and used for the study. The instrument facilitated the conduct of interview of respondents on one-onone basis with the various respondents selected from the mobile telecommunication networks operating in Ghana.

\subsubsection{Sources of Data}

Primary and secondary sources of data were used for the study. Primary data were collected from the field with the use of semi-structured interview guides prepared by the researcher to seek responses that best answers the research questions set out for the study. The questions on the instruments were sectioned according to the various research questions set out for the study. Therefore each section answers a research question. Secondary data were collected from the records of the mobile telecommunication networks. Also, information on the official websites of the mobile telecommunication networks was also used for the study.

\subsubsection{Pre-test}

Instruments were pre-tested using Vodafone regional office in the Takoradi Metropolis. This was done to assess the reliability and validity. Mistakes identified during the pretesting exercise were noted down. Questions with ambiguous meaning were also corrected to ensure easy understanding by all respondents. Validity and reliability of the instruments of the data collection instruments used were confirmed during this exercise.

\subsubsection{Field Work}

Actual fieldwork was done a day after the pre-testing was done. Data collection on field took three days. Two research assistants aided the process. The researcher was the team leader and also part of the data collection team. By role, tem leader supervised all the field work and brought the field strategy to be used.

The final data collected were edited by the filed data collection supervisor. Incomplete instruments were sent back to be fully completed. Serial numbers were provided for all the instruments. This aided the keying of results into the data analysis software.

\subsubsection{Data Analysis}

Descriptive statistics and content analysis were used for data analysis. The statistical package employed for the data analysis was the Statistical Product and Service Solutions (SPSS) software, 19. Microsoft Excel (2013 version) was also used for the study. Likert Scale was used to assess the responses from the respondents. Respondents were asked to rank on a scale of 1 to 3 , the significance of the issues presented on the data collection instruments. 1: represent Disagree, 2: represent neutral, 3: represent Agree. In the words of [23], [2].

Relative importance index was employed to rank the responses.

With relative importance index, frequencies attached to responses were multiplied by their corresponding ranking values (measured from 1 to 3 ) for each factor $(\mathrm{W})$. These were respectively added up $\left(\sum \mathrm{W}\right)$ and subsequently, divided by the product of the total number of respondents $(\mathrm{N})$ and the highest figure or integer on the five point Likert Scale $(A=5)$ [24]. For a three-point response item, RII produces a value ranging from 0.0 to 1.0. Appendix B explains RII formulae as in [25].

\section{Introduction}

Results of data collected are analyzed and presented in this chapter. Further, the findings of the study, which answers the study research questions, are presented and discussed. Respondents were purposively selected based on the judgment of the researcher to select five respondents from each of the six mobile telecommunication companies operating in Ghana. A sample of thirty (30) respondents was 
used for the study. The study begins with the analysis of the socio-demographic characteristics of the respondents. The analysis has been sectioned to correspond to the substantive objectives/ research questions set for the study.

\subsection{Socio-demographic Characteristics of Respondents}

The study looks into the social background of the respondents. The study reveals that all the respondents were married and were ranging between 35 to 45 years of age. All the respondents had more than five years of work experience on the job. The sex distribution of respondents stood at 75 percent for males and 25 percent for females. Making the profession, male dominated. All the respondents had tertiary level education and were all on the rank of management level in their respective organizations. The rest of the analysis focuses on the substantive objectives of the study and have been done under sub-headings.

\subsection{Benefits of Infrastructure Sharing}

The study considered the benefits of sharing infrastructure. Respondents were asked to report the benefits they have received from sharing infrastructure with other networks. The benefits of sharing have been enumerated in this section. These are: Infrastructure sharing speeds up the process of network installation. Cost of building a site is expensive, so with sharing, all the operators come on board and share the cost. Infrastructure sharing is one of the effective strategies of encouraging and promoting cooperation among the different operators in the industry.

Respondents further note benefits such as reduction in operational and capital cost. Reduction in site visits, wide area coverage and ease/ quick site building site. Lastly, sharing of site maintenance is a responsibility.

In a similar study conducted in Nigeria for infrastructure sharing between Mobile Telecommunication Network and Zain Nigeria limited reveals the following benefits [7], which conforms to this study. The benefits includes, but not limited to, low set up cost, wide area coverage, 30 percent reduction in capital expenditure savings and low operational cost (e.g. fuel, electricity etc.). Others include reduction in site visits due to site maintenance and quick to put up site on air.

\subsection{Challenges of Infrastructure Sharing}

Accessibility to the cell site was reported to pose a major problem since each sharing partner gives a different name to the same cell site. Security at the site was also reported to be lows most of the appliance and the devices used at the cell site often gets stolen at the site due to weak security measures from the original owners of the tower.

Timing wasting was reported to be another factor in sharing infrastructure and this result in the agreement processes. Some operators sometimes refuses co-location agreement due to weak towers or that a loaded. Another reason for refusal in share is to gain monopoly in a particular area to boost revenue and increase the number of subscribers. It was also reported that other players use inferior and other infrastructure which makes it incompatible to other sharing operators. Table 2 presents the details on the challenges.

Table 2. Challenges faced by Operators in Infrastructure Sharing.

\begin{tabular}{ll}
\hline Challenges & Percent \\
\hline Inferior equipment & 30 \\
Timing delays & 30 \\
Monopolistic behavior & 22 \\
Security & 15 \\
Accessibility to site & 3 \\
Total & 100 \\
\hline
\end{tabular}

Source: Field data, 2016

Table 2 presents the challenges operators of network face, arranged logically from the highest to the lowest, reflecting the responses from the respondents. These are the regular use of inferior and incompatible equipment (30\%), delays in completing sharing agreements $(30 \%)$ and monopolistic behavior $(22 \%)$ of some operators on the field. These so called "giant operators" refuses to share their infrastructure in order for them to continue to enjoy and maintain monopoly over certain services, thus becomes their competitive advantage tool.

The rest of the challenges, enumerated by the respondents, were security (15\%) and site accessibility (3\%). Respondents complained of frequent loss of equipment and tools on cell sites. With shared sites, each operator has her own engineers. Frequent use and changes with engineers goes with losses of equipment and tools. Lack of uniformity in cell site naming, because of the differences in the names each operator gives to her cell site. This creates problems locating the cell site.

In a similar study on infrastructure sharing between Zain and Mobile Telecommunication Network Nigeria limited reveals [7] the following challenges. These challenges are similar to that of this study. These are: incompatible equipment and inferior equipment. The rest were refusal to share by some of the operators.

\section{Conclusions}

\subsection{Summary of Findings}

The study investigated infrastructure sharing among Ghana's mobile Telecommunication Networks and focused on the benefits and challenges that operators face in the process of sharing infrastructure. The study used all the head offices of the six mobile telecommunication operators in Ghana- viz Globacom (GLO), Mobile Telecommunication Network, Tigo, Vodafone, Airtel and Expresso. Five (5) respondents were purposively selected from the head office of each of the operators, making the total sample size of 30 . All the 30 were in top management position for the firms. Qualitative sampling procedure was used. Interview guide were used on all the respondents. Primary and secondary sources of data were used for the study. Scaling and percentages techniques were used for the data analysis. Key 
findings from the study have been presented here. With respect to the first objectives of the study, the types of infrastructure shared were:

Must is the most shared infrastructure

Space in building is the second most shared infrastructure

Electricity power was the third most shared infrastructure

The least shared infrastructure was: antenna, microwave equipment.

To support the first objective, the study assessed the drivers of sharing among the operators in Ghana. The network operators in Ghana were compelled to share infrastructure because of:

High cost involved in building a cell site. Sharing will allow for sharing of the cost;

Reduction in operational and capital cost of operators;

Promotion of access to areas of strategic importance and also areas considered as under or not served. This helps operators to capture more subscribers.

Promotion is ease in the acquisition of cell site.

With respect to the second objective of the study, the benefit of sharing was:

Speed- up process of network installation, also known as quick in building cell site

Reduced cost of building sells sites

Promotion of corporation among the operators

With respect to the third and the final objective, the challenges linked with sharing infrastructure were:

Inferior equipment used by some of the operators

Delays in the preparation of the sharing agreement

Monopolistic behavior of some of the operators to enjoy competitive advantage

Low security of equipment at cell sites

Lastly, difficulty in accessing cell sites due to the different naming by different operators.

\subsection{Conclusion}

In this current age where information is a key for development, the role of mobile telecommunication industry cannot be downplayed. It is therefore an urgent need to promote and sustain the mobile telecommunication industry, since aside providing a means for communication has also created vast job opportunities to masses of unemployed persons in Ghana and Africa at large. Infrastructure sharing is one of the strategies to adopt to enhance, promote and sustain the mobile telecommunication industry. This study was embarked within this mindset.

The first objective made it real that infrastructure sharing is going on practically among the mobile operators in Ghana. However, the stage is at its lowest levels since only few infrastructures are shared. It can be said that the sharing of infrastructure is still at its infant level.

It was revealed from the second objective that benefits are being derived from the current infrastructure sharing going on among the network operators in Ghana. These benefits have had a positive effect on customers, who now stand the chance to enjoy comparatively cheaper calls and internet service rates, compared with the situation before. Customers are also enjoying better services from the operators. Operators now can focus on core business such as customer service and service quality matters and therefore making lots of profits.

The last objective makes it clear that despite the efforts of promoting infrastructure sharing, the process is bedeviled with problems which hinder its growth. In all, the study and its findings were in line with the conceptual framework developed for the study, which combines the various concepts and theory used for study and also the variables within the empirical reviews. The conceptual framework depicts that drivers of infrastructure sharing gives ways for sharing, epitomized in the various types of infrastructure sharing. And the final result of the sharing is profit making and service improvement. All these were achieved in the study, with respect to its findings.

\section{References}

[1] Addy-Nayo, C. (2001). 3G mobile policy: The case of Ghana.ITU: Geneva, retrieved from www.itu.int/osg/spu/ni/3G/casestudies/ghana/ghanafinal.doc on Jan, 1, 2016.

[2] WSJ (2012). Telecom Giants Battle For Kenya. Retrieved from: http://online.wsj.com/article/SB100014240527487045145045 75612012681373530.html, (Accessed on: January 1, 2016).

[3] Ernst \& Young (n.d) as cited in Ernest IT News Africa (2009). Africa's telecom industry is fastest growing. Retrieved from, http://www.itnewsafrica.com/2009/02/africas-telecomindustry-is-fastest-growing/

[4] Porter, M. E. (1998). The competitive advantage of nations with a new introduction by the author. London: MacMillan Press Ltd.

[5] SAPHYRE. (2010). D5.1a. Contract No.FP7-ICT-248001.

[6] Maitland, C., Bauer, J., \& Westerveld, R. (2002). The European market for mobile data: Evolving value chains and industry structures. Telecommunications Policy, 26(9-10). 485-504.

[7] Onuzuruike E. (2009). Telecom Infrastructure Sharing as a Strategy for Cost Optimization and Revenue Generation: A Case Study of MTN Nigeria/Zain Nigeria Collocation. A thesis submitted to the Blekinge Institute of Technology, for the award of Master degree in Business Administration.

[8] Chanab, L. A. et. al. (2007). Telecom Infrastructure Sharing: Regulatory Enablers and Economic Benefits. Booz Allen Hamilton Consulting, December 2007, pp. 1-12.

[9] Dernab, S. (2011). Telecom Infrastructure Sharing as a Strategy for Cost Optimisation. Thesis submitted to the Kwame Nkrumah University of Science and Technology for the award of Commonwealth Executive Master in Business Administration.

[10] Chanab, L., El-Darwich, B., Hasbani, G. and Mourad, M. (2007). Telecom Infrastructure Sharing: Regulatory Enablers and Economic Benefits. Booz Allen Hamilton Inc.: Available from http://www.boozallen.com/media/file/Telecom_Infrastructure Sharing.pdf (Retrieved July 20, 2014). 
[11] Chatzicharistou, L. (2010). Infrastructure Sharing in Mobile Service Market: Investigating the final decisions of the network operators. Thesis submitted to the Delft University of Technology for the award of Master of Science in Engineering and Policy Analysis.

[12] Bala-Gbogbo, E. (2009). Telecom Industry Operators Opt for Infrastructure Sharing. Access on the $25^{\text {th }}$ day of January, 2016 from the website http://www.234next.com/csp/cms/sites/Next/Money/Business/ $5418647 /$ story.csp

[13] Loizillon, F. et al. (2002). Final Results on Seamless Mobile IP Service Provision. Economics Deliverable number 11. Information Society Technologies.

[14] Northstream. (2001). Network sharing: Savings and Competitive effects. The Swedish Post and Telecom Agency.

[15] Björkdahl, J. \& Bohlin, E. (2003). $3 G$ Network Investments in Sweden. The Swedish Post and Telecom Agency.

[16] Creswell, W. J. (2003). Research design: Qualitative, quantitative and mixed methods approach (2nd edn.). London: Sage Publication.

[17] Creswell, W. J. (2004). Research design: Qualitative, quantitative and mixed methods approach (3nd edn.). London: Sage Publication.
[18] Kusi, H. (2012). Doing Qualitative Research: a Guide for Researchers. Accra: Emmpong Press.

[19] Kuhn, Thomas S. 1964. The structure of scientific revolutions. 3rd edition. Chicago: University of Chicago Press.

[20] Krejcie, R. V., \& Morgan, D. W. (1970). Determining sample size for research activities. Educational and Psychological Measurement, 30 (3), 607-610.

[21] Sarantakos, S. (2005). Social Science Research (3rd edn.). New York: Palgrave Macmillan.

[22] Ayarkwa, J., Dansoh, A. \& Amoah, P. (2010). Barriers to Implementation of EMS in Construction Industry in Ghana. International Journal of Engineering Science, 2(4), pp. 37-45.

[23] Fugar, F. D. \& Agyakwah-Baah, A. B. (2010). Delays in Building Construction Projects in Ghana. Australasian Journal of Construction Economics and Building, 10 (1/2), p. 103-116.

[24] Kothari, R. C. (2004). Research Methodology: Methods and Techniques, ( ${ }^{\text {nd }}$ Edn.). New Delhi: New Age International Publishers.

[25] Muhwezi, L., Acai,. J. \& Otim, G. (2014). An Assessment of the Factors Causing Delays on Building Construction Projects in Uganda. International Journal of Construction Engineering and Management, 3(1), pp. 13-23. 